Original Research Article

\title{
Are we too reluctant about irrational nutraceutical combinations?
}

\author{
V. Krishnan ${ }^{1 *}$, Prakash Murugaiah ${ }^{2}$, Aruna Maria Bachmann ${ }^{3}$
}

${ }^{1}$ Department of Pharmacology, Saveetha Medical College Chennai, India

${ }^{2}$ Department of Pharmacology, Stanley Medical College, Chennai, India

${ }^{3} 2^{\text {nd }}$ Year MBBS Student, Saveetha Medical College Chennai, India

Received: 12 September 2016 Revised: 13 September 2016 Accepted: 20 October 2016

*Correspondence to:

Dr. V. Krishnan,

Email: doctorkrishforu@ gmail.com

Copyright: (C) the author(s), publisher and licensee Medip Academy. This is an openaccess article distributed under the terms of the Creative Commons Attribution NonCommercial License, which permits unrestricted noncommercial use, distribution, and reproduction in any medium, provided the original work is properly cited.

\begin{abstract}
Background: The objective of the study was to study the rationality of Vitamins and minerals combinations available in India and to provide comprehensive data of irrational combinations having excess and sub sufficient quantity of vitamin and minerals than recommended by National Guidelines of India.

Methods: This observational study and analysis was done between June and August 2016. Data was collected from current index of medical specialties and drug India. Rationality assessment was done using National list approved drug combinations by Central drug standard control organization (CDSCO) and essentially was cross checked using World Health Organization essential drug list 2015. Adequacy was analysed using Dietary reference intake (DRI) for Indians by Nutrional council of India draft guidance.

Results: In our analysis, we have found 1184 irrational nutraceutical preparations available in India market. Out of $461(38.9 \%)$ are based on fat soluble vitamins, 190 (16.4\%) based on B-complex vitamins based and 5339 $(45.1 \%)$ related to essential minerals. Among 461 fat soluble vitamins, 104 contain excessive level, 334 contain substandard levels. Similarly 128 and 62 Vitamin B-Complex based preparations are having excess and less quantity than recommended levels respectively and almost all the mineral combinations except four are not prepared following guidelines. None of these combinations were included in National essential list of medicines.

Conclusions: Multivitamins are generally considered safe; these are irrationally prescribed and taken as self-medication by public. Many of the ill effects are often unnoticed and under reported. Government of India should regulate the manufacture and sale these nutraceuticals to promote rational use of drugs and to promote wellbeing and safety of Indian population which is primary objective of 'Health for all'.
\end{abstract}

Keywords: Fixed dose combinations, Hypervitaminosis, Irrational multivitamins, Nutraceuticals

\section{INTRODUCTION}

Following a spree of comments about flourishing irrational fixed dose combinations in Indian market, Government of India, Central drug standard control organization banned 334 fixed dose combinations of drugs that are considered irrational. Fixed dose combinations are considered rational only when combination should act by different mechanisms, their pharmacokinetics must not be widely different and the combination should not have supra-addictive toxicity of the ingredients. Hence, Indian government banned more than three combinations including analgesics, antipyretics, cough suppressants, antihypertensive drugs, antidiabetic drugs and so on. ${ }^{1,2}$
Of the list released by the licensing authorities, none of the combination contains nutraceuticals compounds which are mainly consists of multivitamins and minerals were included. Fixed dose combinations vitamin D with statins like atorvatstatin and zinc with proton pump inhibitors like rabeprazole were the only two banned compounds in the recent list. Beside these two agents with an active chemical moiety, none of combinations exclusive of multivitamins were banned and not even restricted its sale. ${ }^{3}$

Consumption of irrational multivitamins and minerals either by irrational prescription or by self-medication is not safe. Combinations exceeding the prescribed limits can result in cumulative toxicity and combinations that are sub sufficient in doses are not going to benefit our 
patients. If any of these combinations mutual antagonistic substances, then they would be nothing but mere extra cost bearing medication for consumers. National Family health survey and study by Subramnaiyam et al claims that unsupervised nutraceutical combinations escalate the 'double burden' of under nutrition and under nutrition. There are few other evidence based studies multivitamins and mineral compounds are irrationally prescribed and consumed by the patients. These compounds are also topping the list of self-medication by our population due to unrestricted sale on over the counter in various regions. In a study by Chugh PK et al concluded about seventy percent of vitamins and mineral combinations were not according to the specified guidelines and freely available in Indian market. ${ }^{4,5}$

Hence this study was undertaken by us to analyse the rationality and essentiality of currently available nutraceutical compounds.

\section{METHODS}

This Observational study was conducted by Department of Pharmacology, Saveetha Medical College between June and August 2016. The data containing multivitamins and mineral combinations were taken from recent version of current index of medical specialities and drug India update. Content adequacy of nutraceuticals was estimated using dietary reference intake (DRI) given by National institute of nutrition (NIN), Hyderabad, India as well as food and nutrition information centre, United States, Department of Agriculture (USDA). Dietary reference intake includes estimated average requirements (ERA), Recommended Dietary Allowance (RDA) and tolerable upper intake level (UL).

Essentiality and rationality about currently available Nutraceuticals fixed dose was analysed using recent world health organisation (WHO-EML) Essential Medicine list, National Essential list of Medicine India (NLEM) and information official website central drug standard control organisation.

All the data were entered on MS excel and descriptive statistics were adopted to explain the proportion and to infer the significance, non-parametric tests were employed using SPSS version 17 software.

\section{RESULTS}

In our analysis, we have found 1184 irrational nutraceutical preparations available in India market. Out of $461(38.9 \%)$ are based on fat soluble vitamins, 190 (16.4\%) based on B-complex vitamins based and 539 $(45.1 \%)$ related to essential minerals. Among 461 fat soluble vitamins, 104 contain excessive level and 334 contain sub-standard levels. Similarly 128 and 62 Vitamin B-Complex based preparations are having excess and less quantity than recommended levels respectively and almost all the mineral combinations except four are prepared following guidelines. None of these combinations were included in National essential list of medicines and World Health Organization essential fixed dose combinations.

Table 1: Extent of fixed dose rational and irrational combinations of vitamin and minerals.

\begin{tabular}{|lllll|}
\hline Vitamins and Minerals & $\begin{array}{l}\text { Total No of } \\
\text { FDCs }\end{array}$ & $\begin{array}{l}\text { Increased level in } \\
\text { FDCs }\end{array}$ & $\begin{array}{l}\text { Decreased } \\
\text { level in FDCs }\end{array}$ & $\begin{array}{c}\text { Equal to DRI } \\
\text { Vitamin A }\end{array}$ \\
\hline Vitamin D & 164 & 43 & 118 & 1 \\
\hline Vitamin E & 146 & 6 & 87 & 9 \\
\hline Iron & 151 & 55 & 7 & 1 \\
\hline Zinc & 60 & 52 & 84 & 2 \\
\hline Selenium & 221 & 135 & 61 & 1 \\
\hline Calcium & 133 & 71 & 117 & 1 \\
\hline B Complex vitamins & 119 & 1 & 62 & - \\
\hline
\end{tabular}

Sub group analysis showed vitamin $\mathrm{A}$ is added in this combination in a greater proportion $(26.2 \%)$ then dietary reference intake followed by Vitamin $\mathrm{D}$; however vitamin $\mathrm{D}$ is also sub sufficient in many combinations $(95.2 \%)$ among fat soluble vitamins. Calcium which is often combined with vitamin D combination is also sub sufficient and zinc is added extra in majority $(66.1 \%)$ of compositions.
More than two third of iron preparations and vitamin B complex preparations are having greater amount than the reference level but extent to which they cater individual is sub optimal when given combinations, details of which is presented in our discussion vide infra. 


\section{DISCUSSION}

\section{Briefing and corroboration}

Nutraceutical by definition are functional foods, they are expected to provide health benefits through as fortified foods or as dietary supplements, including as drugs/medication. These compounds are marketed with no rationality in combination and such combinations do not confer any benefits unless they are specifically indicated with documented deficient for a patient. Irrational prescription and self-consumption of multivitamins are increasing in developed and developing nations as well..$^{6-8}$ A study findings revealed more than eight percent of multivitamins and minerals pharmaceutical preparations are not according to the specified guidelines. A study conducted Balat JD et al also concluded $81.5 \%$ of fixed dose combinations are irrational which also includes nutraceutical preparations. The daily divided doses of $100 \mathrm{mg}$ of elemental iron are never provided by such irrational combinations. Similar scenario is seen in case of zinc and selenium in content in these pharmaceutical preparations. Karelia BN analysis of exclusive of hemetinics preparations itself proven to be rational only twenty four percent among all the hemetinics preparations available in Indian market. ${ }^{8,9}$

\section{Implications}

Vitamin A and D preparations are widely varying in their composition, though their composition contain lesser amounts it must be remembered that dietary reference intake includes the recommended daily allowance as well as tolerable upper level. These fat soluble vitamins tend to accumulative tin the body and can result in hyperviatminosis.

Vitamin A and D toxicity are often under recognized in our setting but they are not trivial. In the west there are well documented case series and case reports to support our discussion. Lauren et al discussed case series of hypervitaminosis A and its impact on New England Journal of Medicine in March 2016. Vitamin D toxicity can affect many biological systems causing nephrocalcinosis, neuropsychiatric complication and can cause fatal cardiac arrest. Case series by Koul PA et al found nine of ten cases of hypercalcaemia are due to Vitamin D toxicity. ${ }^{11-13}$

In vitro pharmaceutical interactions are well known. In a nutraceutical combination, extent to which iron and calcium absorb and be beneficial to the patient is questionable. Zinc absorption is also affected when given with multivitamin combinations and its inclusion becomes purposeless.

The therapeutic non beneficial drug-nutraceutical preparation poses higher threats as these are often consumed by patients themselves. Niacin intensifying myopathy related adverse effects of statins and pyridoxine affecting levodopa availability are well known. Beside these, there are new findings on nutraceuticals and drug interactions like folic acid reducing phenytoin antiseizure activity, pyridoxine increasing amiodarone skin rashes, ascorbic acid increases aluminium and magnesium absorption and causes toxicity in renal failure patients, iron and zinc reduces the effectiveness of ciprofloxacin, levofloxacin, norfloxacin, moxifloxacin and Vitamin A increases anticoagulant action of warfarin and newer anticoagulants like direct thrombin inhibitors and can result in bleeding etc. ${ }^{14-16}$

\section{CONCLUSION}

Nearly eighty percent multivitamins and minerals fixed dose combinations are free flowing in market. Legislative and educational measures must be taken to curtail their use for the sake of wellbeing of our population.

Funding: No funding sources

Conflict of interest: None declared

Ethical approval: Not required

\section{REFERENCES}

1. McGettigan P, Roderick P, Mahajan R, Kadam A, Pollock AM. Use of Fixed Dose Combination (FDC) Drugs in India: Central Regulatory Approval and Sales of FDCs Containing Non-Steroidal AntiInflammatory Drugs (NSAIDs), Metformin, or Psychotropic Drugs. Kesselheim AS, ed. PLoS Medicine. 2015;12(5):e1001826.

2. Gautam CS, Saha L. Fixed dose drug combinations (FDCs): rational or irrational: a view point. British Journal of Clinical Pharmacology. 2008;65(5):795-6.

3. Central Drug Standard Control Organization. [Updated Aug 2016, Cited 26 Aug 206 ]. Available from: http://www.cdsco.nic.in/forms/Default.aspx

4. Subramanian SV, Kawachi I. Income inequality and the double burden of under- and overnutrition in India. Journal of Epidemiology and Community Health. 2007;61(9):802-9.

5. Chugh PK, Lhamo Y. An Assessment of Vitamin Supplements in the Indian Market. Indian Journal of Pharmaceutical Sciences. 2012;74(5):469-73.

6. Bailey RL, Gahche JJ, Lentino CV, Dwyer JT, Engel JS, Thomas PR, Betz JM, Sempos CT, Picciano MF: Dietary supplement use in the United States, 20032006. J Nutr. 2011;141:261-6.

7. Bailey RL, Gahche JJ, Miller PE, Thomas PR, Dwyer JT: Why US adults use dietary supplements. JAMA Intern Med. 2013;173:355-61.

8. Gahche J, Bailey R, Burt V, Hughes J, Yetley E, Dwyer J, Picciano MF, McDowell M, Sempos C: Dietary supplement use among U.S. adults has increased since NHANES III (1988-1994). NCHS Data Brief. 2011;61:1-8.

9. Karelia BN, Buch JG. Analysis of hematinic formulations available in the Indian market. Journal 
of Pharmacology and Pharmacotherapeutics. 2012;3(1):35-8.

10. Balat JD, Gandhi AM, Patel PP, Dikshit RK. A study of use of fixed dose combinations in Ahmedabad, India. Indian Journal of Pharmacology. 2014;46(5):503-9.

11. Beste LA, Moseley RH. Too Much of a Good Thing. N Engl J Med. 2016;374:873-8.

12. Garg G, Khadgwat R, Khandelwal D, Gupta N. Vitamin D toxicity presenting as hypercalcemia and complete heart block: An interesting case report. Indian J Endocr Metab. 2012;16(Suppl S2):423-5

13. Koul PA, Ahmad SH, Ahmad F, Jan RA, Shah SU, Khan UH. Vitamin D Toxicity in Adults: A Case Series from an Area with Endemic Hypovitaminosis D. Oman Medical Journal. 2011;26(3):201-4.

14. Elizabeth A Yetle .Multivitamin and multimineral dietary supplements: definitions, characterization, bioavailability, and drug interactions. Am J Clin Nutr January 2007 vol. 85 no. 1269 S-276S

15. Ames BN: Low micronutrient intake may accelerate the degenerative diseases of aging through allocation of scarce micronutrients by triage. Proc Natl Acad Sci U S A. 2006; 103:17589-94.

16. Yetley EA. Multivitamin and multimineral dietary supplements: definitions, characterization, bioavailability, and drug interactions. Am J Clin Nutr. 2007;85:269S-76S.

17. Jadav SP, Parmar DM. Critical appraisal of irrational drug combinations: A call for awareness in undergraduate medical students. Journal of Pharmacology and Pharmacotherapeutics. 2011;2(1):45-8.

18. Sharma K, Sharma A, Singh V, Pilania D, Sharma YK. Irrational Fixed Dose Combinations and Need for Intervention: Understanding of Dental Clinicians and Residents. JCDR. 2014;8(12):ZC49-52.

19. Goswami N, Gandhi A, Patel P, Dikshit R. An evaluation of knowledge, attitude and practices about prescribing fixed dose combinations among resident doctors. Perspectives in Clinical Research. 2013;4(2):130-5.

Cite this article as: Krishnan V, Murugaiah $\mathrm{P}$, Bachmann AM. Are we too reluctant about irrational nutraceutical combinations? Int J Basic Clin Pharmacol 2016;5:2585-8. 